\title{
TRANSFORMACJA MIASTA I JEGO WIZERUNKU NA PODSTAWIE KULTURY. STUDIUM TURECKIEGO ESKIŞEHIRU
}

\author{
Abstract \\ URBAN TRANSFORMATION AND A CHANGE OF A CITY IMAGE THROUGH \\ CULTURE. THE CASE OF TURKISH ESKIŞEHIR
}

In the last decade, Turkey has experienced drastic changes in the area of culture and cultural heritage. A vivid revivial in the discourse and practices related to culture can be observed at the national as well as local level. The paper presents an analysis of the role culture plays in urban development as exemplified by one of the Turkish cities, which, due to an engaged mayor and his widely promoted vision of development based on culture, has been undergoing significant transformation. Eskişehir - a city associated in the 20th century primarily with industry - is nowadays aiming at becoming one of the leading places in art and culture in the country. The main goal of the article is to analyze the ways in which local authorities in Eskişehir relate to culture and take advantage of the cultural heritage of the city and its province (both tangible and intangible). Moreover, the paper discusses various determinants both conduicive and obstructive to the particular development pattern of the city.

SŁOWA KLUCZE: Turcja, kultura, rozwój, Eskişehir, osmańskie dziedzictwo architektoniczne, lista UNESCO, dziedzictwo sufickie

KEY WORDS: Turkey, culture, development, Eskişehir, Osman architectural heritage, UNESCO list, Sufi heritage

\section{Wstęp}

Od 2002 roku, gdy władzę w Turcji przejęła Partia Sprawiedliwości i Rozwoju (Adalet ve Kalkınma Partisi, AKP), państwo to doświadcza głębokich zmian w polityce, praktyce i dyskursie w sferze kultury oraz dziedzictwa kulturowego. Powstają wizje, nowe idee, programy i projekty wyrażające różne aspiracje odnośnie 
do sposobów włączenia kultury w procesy rozwojowe. Zmiany idące w różnych kierunkach, czasem sprzecznych z sobą, są widoczne i na szczeblu państwowym, i lokalnym. Coraz więcej aktorów społecznych włącza się w dyskusje i prace na rzecz ochrony czy promocji dziedzictwa kulturowego, co szczególnie widać na poziomie lokalnym.

Polityka turecka w sferze kultury nabrała wyrazistości w pierwszej dekadzie XXI wieku. Wyraźnie widać ożywione zainteresowanie dziedzictwem kulturowym, które przez długi czas było kwestią marginalną w debacie publicznej. Kontrowersje związane z transformacją zabytkowych dzielnic czy budynków są nagłaśniane przez media i wywołują dyskusje (np. rewitalizacja historycznych dzielnic w Stambule czy odkrycia archeologiczne dokonywane w trakcie budowy infrastruktury komunikacyjnej). Powstają nowe stowarzyszenia oraz instytucje zajmujące się problematyką szeroko rozumianej kultury i wieloma współcześnie nagłaśnianymi problematycznymi kwestiami, takimi jak demokratyzacja kultury czy status kultur mniejszości narodowych, etnicznych i religijnych.

Na praktyki i dyskurs dziedzictwa wpłynęły podjęte w latach osiemdziesiątych XX wieku reformy, które wprowadził Turgut Özal i kierowana przez niego Partia Ojczyźniana (Anavatan Partisi). Był to okres intensywnej liberalizacji gospodarczej i otwarcia na globalizację. Przekazanie wielu zadań w obszarze kultury podmiotom na szczeblu lokalnym przełożyło się na włączenie różnych aktorów zainteresowanych dziedzictwem kulturowym, w tym administracji lokalnej, organizacji trzeciego sektora i osób prywatnych. Zmiany prawne uczyniły z metropolii ważne podmioty w tureckiej polityce kulturalnej. W oficjalnym dyskursie rola państwa ulegała zmniejszeniu - podkreślano odchodzenie od wizji centralnie narzucanego programu kulturowego. Postępująca demokratyzacja oznaczała otwieranie się na różne idee i propozycje. Dużą rolę w promowaniu nowych dla Turcji idei miały organizacje pozarządowe, których działania w latach dziewięćdziesiątych ubiegłego wieku nabrały dynamizmu'.

Jean-François Polo i Füsun Üstel, analizując rozwój polityk kulturalnych Turcji, uznali moment objęcia władzy w państwie przez AKP za ważną cezurę, rozpoczynającą nowy etap zarówno w dziedzinie kultury, jak i wielu innych - zwłaszcza w gospodarce, prawie, rozwoju infrastruktury i w systemie politycznym² ${ }^{2}$ Wizja AKP zawiera nową dla Turcji perspektywę patrzenia na przeszłość i jej znaczenie dla społeczeństwa. Dziedzictwo oraz jego ochrona stają się przedmiotem pragmatycznych interesów i postrzegane są przez pryzmat wielorakich korzyści, jakie można za ich pomocą uzyskać. Szczególnie wyraźne jest wykorzystanie wybranych elementów dziedzictwa w promocji i dyplomacji międzynarodowej, co ma się przełożyć na pozytywny wizerunek kraju zarówno w kontekście procesu negocjacji akcesyjnych

${ }^{1}$ A. Ince, Cultural Centers in Istanbul: Changing Cultural Policies in the 2000s [w:] A. Ince (red.), Cultural Policy and Management: Yearbook 2010, Istanbul 2010.

2 J.-F. Polo, F. Üstel, Les nouvelles orientations de la politique culturelle turque sous l'AKP, „Pôle Sud-Revue de science politique de l'Europe méridionale” 2014, nr 41, s. 17-32. 
z Unią Europejską, jak i wśród turystów zagranicznych, bardzo ważnych dla gospodarki tureckiej³.

AKP w swoim programie odnoszącym się do kultury i dziedzictwa kulturowego podkreślała w pierwszych latach swoich rządów znaczenie globalizacji i prywatyzacji. Wyraźne było zainteresowanie możliwościami partnerstwa z aktorami prywatnymi i zachęcanie przedsiębiorców do inwestycji w kulturę. Służyły temu zmiany w przepisach prawnych, które m.in. umożliwiły sponsorom oraz inwestorom skorzystanie ze zniżek podatkowych. Proces częściowego wycofywania się państwa ze sfery kultury był też widoczny w sektorze pozarządowym, z którym również wiązano oczekiwania i nadzieje na wspólne działania na rzecz zachowania, rewitalizacji czy promocji elementów kultury4.

Zacieśnianie się relacji między Turcją a UE było u progu XXI wieku jednym z ważniejszych czynników, które spowodowały, że kultura stała się tematem politycznym, a polityka kulturalna nabrała wyraźnego charakteru. Negocjacje akcesyjne i realne perspektywy integracji Turcji ze strukturami UE na początku bieżącego stulecia niewątpliwie wpłynęły na proces ,europeizacji” zarządzania kulturą i dziedzictwem kulturowym oraz upodabniania się rozwiązań w tej sferze. Konwergencję widać m.in. w projektach rozwojowych, których ważnymi elementami stały się ochrona i rewitalizacja dziedzictwa kulturowego, a także włączenie w te działania społeczności lokalnej5.

Ważnym trendem globalnym, w który Turcja $\mathrm{z}$ powodzeniem się wpisuje - zwłaszcza w ostatniej dekadzie - jest dywersyfikacja form turystyki i wzrost zainteresowania turystyką kulturalną zarówno ze strony turystów zagranicznych, jak i krajowych. Dużą rolę odgrywają miejsca uznane oficjalnie przez UNESCO za "dziedzictwo kulturowe" (tureckich obiektów na Liście Światowego Dziedzictwa jest obecnie $16^{6}$ ), które na całym świecie są magnesem przyciągającym podróżujących. Strategia Rozwoju Turystyki Turcji na lata 2013-20237, którą przygotowało Ministerstwo Kultury i Turystyki, przewiduje dalszą dynamikę sektora turystycznego i jego coraz większy udział w gospodarce państwa. Według planów rządu, celem jest taki wzrost liczby turystów, aby Turcja stała się jedną z pięciu największych marek turystycznych świata. Ważne zadanie stanowi promocja mniej znanych zakątków

${ }^{3}$ R. Kurpiewska-Korbut, Dziedzictwo kulturowe jako element promocji międzynarodowej i polityki rozwojowej Turcji, „Zarządzanie w Kulturze” 2012, nr 13, t. 1.

${ }^{4}$ A. Aksoy, A mindshift [w:] S. Ada, H.A. İnce (red.), Introduction to cultural policy in Turkey, Istanbul 2009.

${ }_{5}$ Taka sytuacja jest np. w Projekcie Anatolii Południowo-Wschodniej, w którym Komisja Europejska przez „Program Rozwoju Dziedzictwa Kulturowego Regionu GAP” wsparła lokalne inicjatywy i przedsięwzięcia zmierzające do ochrony dziedzictwa kulturowego i wykorzystania go jako narzędzia rozwoju turystyki. D. Wiktor-Mach, Dziedzictwo kulturowe a rozwój. Dylematy i wyzwania na przyktadzie Turcji [w:] K. Jarecka-Stępień, A. Surdej (red.), Tożsamość i efektywność: w poszukiwaniu mechanizmów zrównoważonego rozwoju, Toruń 2016.

${ }^{6}$ Stan na lipiec $2016 \mathrm{r}$.

7 Ministry of Culture and Tourism, Tourism strategy of Turkey 2013, Ankara 2007, https:// www.kultur.gov.tr/Eklenti/43537,turkeytourismstrategy2023pdf.pdf?0\&_tag1=796689BB12A540BE0672E65E48D10C07D6DAE291 [odczyt: 1.09.2016]. 
kraju, zwłaszcza historycznych miejsc położonych na wschodzie. Ma to być szansa dla mniejszych miast i regionów, które są zdominowane przez główne ośrodki turystyczne, przede wszystkim Stambuł. Kultura i sztuka są uważane przez rządzących za użyteczne narzędzia w brandingu i kreowaniu wizerunku miejsca - zarówno miast, jak i prowincji mających cenne zasoby dziedzictwa kulturowego. Ta wizja pragmatycznego wykorzystania zabytków kultury wpisuje się od początku w program kulturalny AKP i jest jednym z bardziej dostrzegalnych kierunków. Nie wiadomo jednak, w jakim stopniu uda się zrealizować te plany w obliczu problemów politycznych, które nasiliły się po próbie zamachu stanu z 15 lipca 2016 roku. Zamachy terrorystyczne, wojna z kurdyjską PKK oraz zaangażowanie Turcji w wojnę w Syrii drastycznie zmniejszyły poziom bezpieczeństwa i wpłynęły na spadek liczby turystów zagranicznych.

Mimo obserwowanych w Turcji procesów decentralizacji, wielu badaczy podkreśla niejednoznaczny charakter tych zmian. Eksperci Rady Europy zwracają uwagę na niewykorzystany potencjał władz lokalnych w dziedzinie kultury ${ }^{8}$. Sara Bonini Baraldi, Daniel Shoup i Luca Zan po przeanalizowaniu systemu instytucjonalnego ochrony dziedzictwa kulturowego doszli do wniosku, że głównymi jego cechami są: centralizacja i fragmentacja działań. Mimo reform z początku XXI wieku, bardzo dużą rolę na szczeblu lokalnym odgrywa nieustannie Ministerstwo Kultury i Turystyki, a administracja lokalna jest tylko jednym z wielu podmiotów, które decydują o kulturze w danym miejscu? .

Pomimo ograniczonych możliwości i powolnej decentralizacji, władze lokalne mają jednak spory obszar wolności w sferze kultury. Inicjatywy i zaangażowanie aktorów miejskich mogą wpłynąć pozytywnie na podniesienie rangi kultury i uczynienie z niej zasobu rozwojowego. Artykuł ten prezentuje przypadek jednego z miast w Turcji, które za sprawą wizjonerskiego lidera - burmistrza i szeroko propagowanej przez niego i związane z nim środowisko wizji rozwoju na podstawie kultury przeszło w ostatniej dekadzie znaczącą transformację. Eskişehir to miasto, które w XX wieku kojarzone było głównie z przemysłem, a obecnie ma ambicje stania się jednym z czołowych krajowych ośrodków sztuki i kultury. Przedstawione tu zostaną uwarunkowania sprzyjające rozwojowi miasta w tym kierunku. Pokażę, jak władze lokalne w Eskişehirze wykorzystują dziedzictwo kulturowe miasta i okolic. Ostatnia dekada to dla całej Turcji okres gwałtownych przeobrażeń w sferze kultury i w zarządzaniu nią, a przykład Eskişehiru pokazuje, jak niejednoznaczne są to zmiany.

${ }^{8}$ Council of Europe, Presentation of the cultural policy review of Turkey, Strasbourg 2013, s. 30-32, http://www.coe.int/t/dg4/cultureheritage/culture/Reviews/CDCPP-Bu-2013-2_Turkeyexperts_en.pdf [odczyt: 1.09.2016].

9 B. Baraldi, S. Shoup, D.L. Zan, Understanding cultural heritage in Turkey: institutional context and organisational Issues, „International Journal of Heritage Studies”2013, nr 19(7), s. 728-748. 


\section{Eskişehir - od miasta przemysłowego do miasta kultury i sztuki}

Eskişehir, miasto leżące w środkowej Anatolii, w XX wieku było przede wszystkim ważnym ośrodkiem przemysłu tureckiego. Podczas wojny o niepodległość (1919-1923) było ono miejscem walk, doznało poważnych zniszczeń, lecz po odbudowie nie widać wielu śladów starożytnych korzeni miasta i jego wielowiekowej, bogatej historii. Warto wspomnieć, iż Eskişehir to jedno z najstarszych miast w Turcji, a jego początki łączą się ze starożytnym miastem Dorylaeum ${ }^{10}$. Gdy w początkowym okresie Republiki Kemal Atatürk podjął wysiłki w kierunku osiągnięcia samowystarczalności gospodarczej kraju, Eskişehir znalazł się wśród pierwszych miast anatolijskich, z których władze republiki postanowiły uczynić bazę industrialną dla całej Turcji. W latach 1923-1950 w całym kraju nastąpiła dynamiczna industrializacja. Inwestycje państwowe zapewniły szybki i gwałtowny rozwój, a regiony, w których lokowano produkcję przemysłową - zwłaszcza Stambuł, Izmir, Kayseri, Sivasie, Karabüku, Kirikkale i właśnie Eskişehir - doświadczyły głębokich przemian ${ }^{11}$.

W Anatolii osadzani byli masowo Turcy i muzułmańscy mieszkańcy terenów dawnego Imperium Osmańskiego w ramach polityki nacjonalizacji powstającej Republiki Tureckiej. Struktura demograficzna Eskişehiru uległa dalszemu zróżnicowaniu etnicznemu za sprawą m.in. Tatarów, ludów kaukaskich oraz muzułmańskich osadników z Bałkanów (zwanych muhacirami, z arab. migrantami) ${ }^{12}$. Duże fale migracyjne przekładały się na wzrost liczby mieszkańców miasta i okolic. Ludzie znajdywali pracę w fabrykach powstających w pierwszych latach funkcjonowania Republiki.

W ostatnich dekadach XX wieku Eskişehir znacznie podupadł i stracił wiele ze swojej wcześniejszej dynamiki. Podobnie jak cała Anatolia, która długo była kojarzona z zacofaniem, biedą i zastojem, tak samo Eskişehir - mimo statusu miasta i relatywnie dużej liczby mieszańców - był raczej powszechnie kojarzony z „dużą wsią” i brakiem potencjału rozwojowego ${ }^{13}$. Centrum miasta, przez którego środek płynie rzeka Porsuk, nie było atrakcyjnym miejscem ani do mieszkania, ani do spędzania wolnego czasu. Do tego obrazu przyczyniła się też związana z industrializacją masowa migracja ze wsi do miast. Turyści przybywali do okolicznych miast, a Eskişehir najczęściej omijali, nie znajdując w nim nic wartego zobaczenia. Poprawa sytuacji gospodarczej miasta, podobnie jak kilku innych miast Anatolii, nastąpiła wraz z procesem transformacji i restrukturyzacji gospodarki państwa rozpoczętej w latach osiemdziesiątych XX wieku. Nowy model gospodarczy wynikający ze spadku znaczenia państwa w krajowej gospodarce wymagał wzięcia inicjatywy we własne ręce.

${ }^{10}$ Historia miasta jest przedstawiona w m.in. S. Dönmezer, An Example of Art-Culture Policy City: Eskişehir, „International Journal of Humanities and Social Science” 2012, nr 2(2), s. 56-58.

${ }_{11}$ M. Bazin, S. de Tapia, Turcja. Geografia wschodzacej potęgi, Warszawa 2014, s. 151-152.

12 Masowe przyjazdy z Krymu i z Kaukazu na terytorium dzisiejszej Turcji na dużą skalę odbywały się już wcześniej w historii, a zwłaszcza w XIX w.

${ }_{13}$ Eskişehir Büyükşehir Belediyesi, Stratejik Plan 2010 (2006-2010), http://www.eskisehir. bel.tr/dosyalar/stratejik_plan/2010.pdf [odczyt: 2.06.2016]. 
Ważny impuls do zmiany dla Eskişehiru pojawił się w roku 1999 wraz z wyborem na burmistrza miasta prof. Yılmaza Büyükerşena ${ }^{14}$ - naukowca, byłego rektora Uniwersytetu Anatolijskiego i artysty, który miał wiele pomysłów na rozwój miasta i wizję szeroko zakrojonych zmian. Pod jego przywództwem i za sprawą jego inspiracji oraz zaangażowania udało się przeprowadzić renowację miasta na wysokim poziomie, przez co stało się ono modelem transformacji dla wielu ośrodków tureckich. Miasto doświadczyło przeobrażeń w wielu aspektach - od zmian w wyglądzie przestrzeni publicznej, przez przebudowę centrum, a także powstanie wielu nowych inwestycji, aż po położenie akcentu na kulturę i sztukę. Wizja miasta przedstawiona na jego oficjalnej stronie internetowej akcentuje status Eskişehiru jako miasta wzorcowego dla innych miast tureckich ${ }^{15}$.

Büyükerşen cieszy się tak dużym poparciem wśród mieszkańców, że już czwarty raz z rzędu wygrał wybory na burmistrza miasta $(1999,2004,2009,2014)$. Aby docenić ten sukces, trzeba dodać, że nie startował on z listy, rządzącej państwem od 2002 roku, Partii Sprawiedliwości i Rozwoju, lecz związany był od początku ze środowiskiem lewicowym i socjaldemokratycznym. W trzech pierwszych wyborach, w których wygrał, występował z ramienia Partii Demokratycznej Lewicy (Demokratik Sol Parti - DSP). W roku 2014 wystartował natomiast z listy Republikańskiej Partii Ludowej (Cumhuriyet Halk Partisi, CHP). W tym samym roku w wyborach lokalnych CHP odniosła też sukces w gminie Odunpazarı, na której terenie są zabytkowe domy z czasów osmańskich.

Choć na sukces miasta pracuje wiele osób z różnych organów administracji lokalnej, to w powszechnym odczuciu transformacja przypisywana jest właśnie burmistrzowi miasta. Büyükerşen jest uważany za inspiratora i za silnego lidera mającego wizję oraz możliwości, aby ją wprowadzać w życie. Y1lmaz Büyükerşen urodził się w Eskişehirze w 1937 roku. Studiował na Akademii Nauk Ekonomicznych i Handlowych, którą ukończył w roku 1962. Podczas studiów pracował jako dziennikarz dla różnych gazet. Cztery lata później został doktorem filozofii, a w 1973 roku uzyskał tytuł profesora. W latach osiemdziesiątych XX wieku dwukrotnie został wybrany na rektora Uniwersytetu Anatolijskiego i podczas swoich kadencji rozwijał wydziały związane ze sztuką, literaturą, komunikacją. Stworzył też zakończony sukcesem system edukacji zdalnej, z którego korzystają tysiące studentów. Sam jest artystą specjalizującym się w rzeźbieniu w wosku - wyrzeźbił m.in. słynny posąg Atatürka znajdujący się w mauzoleum Anıtkabir. Do polityki trafił w wieku 62 lat, po latach różnorodnych doświadczeń w sektorze nauki i edukacji, gdy w 1999 roku został wybrany na burmistrza Eskişehiru (il. 1) ${ }^{16}$.

${ }^{14}$ Büyükerşen został wybrany na burmistrza miasta metropolitalnego Eskişehir (Eskişehir Büyükşehir Belediyesi). Osobnymi jednostkami administracyjnymi są: gmina Odunpazarı (Eskişehir Odunpazarı Belediyesi) i gmina Tepebaşı (Eskişehir Tepebaşı Belediyesi).

15 Eskişehir Büyükşehir Belediyesi, Kurumsal Vizyonumu ve Misyonumuz, http://www.eskisehir.bel.tr/sayfalar.php?sayfalar_id=7 [odczyt: 2.06.2016].

16 Başkan Biografi, Prof. Dr. Yılmaz BÜYÜKERŞEN, http://www.eskisehir.bel.tr/sayfalar. php?sayfalar_id=3 [odczyt: 2.06.2016]. 


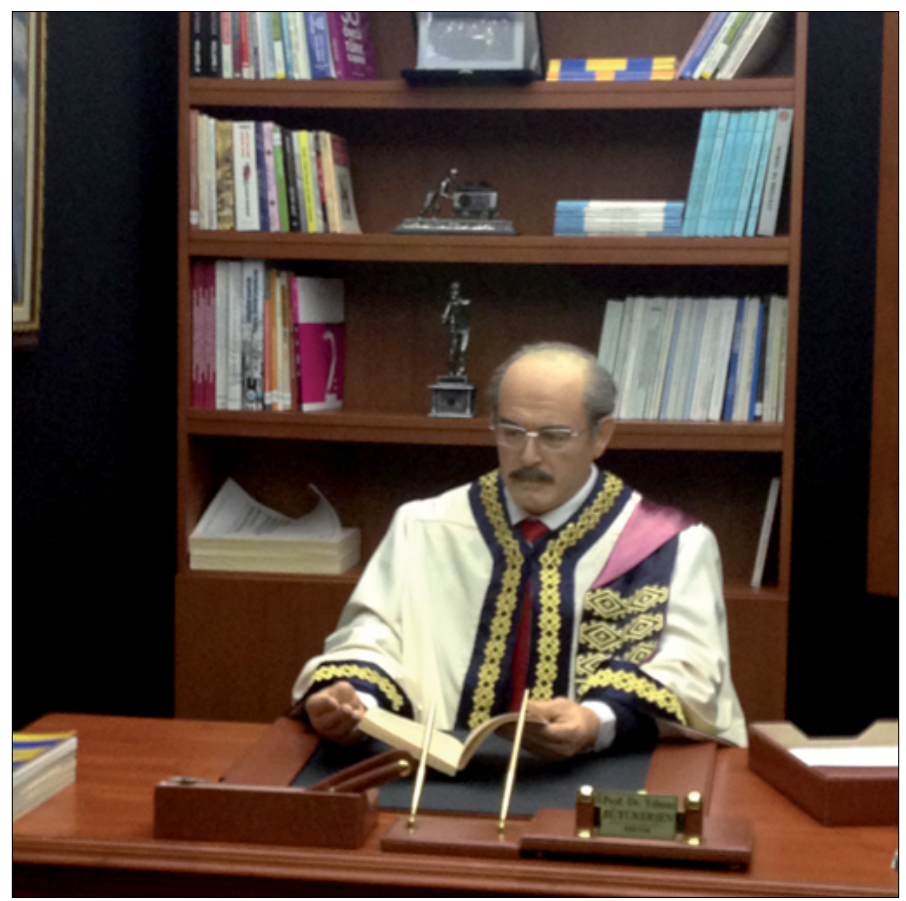

II. 1. Rzeźba z wosku przedstawiająca burmistrza Eskişehiru, prof. Yılmaza Büyükerşena (Muzeum Figur Woskowych, Balmumu Heykeller Muzesi, Eskişehir)

Büyükerşen w swojej wizji rozwoju podkreśla, że chce uczynić z Eskişehiru miasto o standardach europejskich, ale osadzone w swojej tradycji i historii. Wśród swoich celów wymienia dążenie do przekształcenia miasta, którym zarządza, w lidera wśród miast tureckich, a także wykorzystanie historii, kultury i przemysłu miasta do skutecznego konkurowania z innymi ośrodkami miejskimi ${ }^{17}$. Położenie silnego akcentu na obszar kultury okazało się efektywnym zabiegiem i pomogło w zmianie wizerunku miasta, zarówno wśród mieszkańców, studentów, jak i turystów.

\section{Uwarunkowania rozwoju Eskişehiru na podstawie kultury}

Troska o dziedzictwo kulturowe i rozmaite przedsięwzięcia w sferze kultury współczesnej ściśle wiążą się z ważnym miejscem branży turystycznej w rozwoju miasta. Wprawdzie turyści zagraniczni przyjeżdżają przede wszystkim do kilku

${ }^{17} \mathrm{H}$. Babadoğan, Urban project's implementations Towards a European City: A Case Analysis of Eskişehir Greater Municipality, Master Thesis in Urban Policy planning and Local Governments, M.E.T.U, Ankara 2005, s. 111. 
regionów - do Stambułu, na wybrzeże Morza Egejskiego i Morza Śródziemnego oraz do Kapadocji, lecz turyści krajowi szukają nowych miejsc i coraz chętniej podróżują, przejawiając zwiększone zainteresowanie miejscami dziedzictwa kulturowego i przyrodniczego ich kraju. Korzystają przy tym z dynamicznie rozwijającej się sieci transportowej. Kilka lat temu uruchomiona została linia szybkiej kolei (Yüksek Hızlı Tren, YHT) łącząca Ankarę ze Stambułem, której trasa przebiega właśnie przez Eskişehir. Kolej ta była budowana etapami, z których pierwszy pomiędzy Ankarą a Eskişehirem oddano do użytku w roku 2009, a kolejny - łączący Eskişehir ze Stambułem w 2014. Stanowi to część gigantycznych projektów inwestycyjnych, budowy lotnisk, autostrad, torów kolejowych obejmujących całą Turcję, które rewolucjonizują sposób podróżowania po kraju. Bardzo wygodne połączenie zintensyfikowało kontakty między mieszkańcami miast leżących na trasie YHT w wielu aspektach życia. Od tego czasu wśród ludzi ze stolicy popularne stały się wyjazdy weekendowe do Eskişehiru.

Wśród czynników wpływających na politykę kulturalną trzeba również wziąć pod uwagę sytuację demograficzną miasta. Pod względem liczebności populacji nie należy ono do największych ośrodków urbanistycznych w Turcji (według danych z 2014 roku liczba mieszkańców wynosi $812320^{18}$ ), niemniej jednak jest ważnym ośrodkiem przyciągającym migrantów zarówno z kraju, jak i zagranicy. Szacuje się, że ponad połowa mieszkańców ma korzenie bałkańskie, kaukaskie lub krymskie. Jest też Eskişehir centrum życia studenckiego. Działają w nim dwa publiczne uniwersytety - Uniwersytet Anatolijski (Anadolu Üniversitesi), którego początki sięgają roku 1958, a status uniwersytetu uzyskał w 1982, i Eskişehir Osmangazi Üniversitesi (ESOGU), który formalnie powstał w 1993 roku. Studiuje na nich łącznie około 55 tysięcy osób ${ }^{19}$, co dodaje miastu dynamizmu oraz stwarza atmosferę kultury młodzieżowej i akademickiej. W porównaniu z innymi miastami wysoki jest odsetek osób z wyższym wykształceniem, co przekłada się na poziom kapitału społecznego i ekonomicznego miasta. Przewodniki po Turcji opisują Eskişehir jako miasto pełne życia, młode, progresywne, z klimatem tolerancji i otwartości na innych ludzi. Uniwersytety pełnią również ważną funkcję w polityce miejskiej. Büyükerşen, jako były rektor Uniwersytetu Anatolijskiego, korzysta z relacji ze światem akademickim i współpracuje z nim w wielu wymiarach. Gdy zaczynał pracę jako burmistrz, zapraszał przedstawicieli uniwersytetów na seminaria i konferencje poświęcone wymianie opinii na temat problemów miasta oraz jego potrzeb ${ }^{20}$.

Współczesny Eskişehir - jak już wspomniałam - nie jest miastem, które można określić mianem miasta historycznego, z wieloma zabytkami czy dzielnicami noszącymi ślady przeszłości. Wyjąatkiem jest Odunpazarı - część miasta z tradycyjnymi domami z czasów osmańskich. Mimo to władze lokalne starają się ostatnimi czasy

${ }_{18}$ Eskişehir Büyükşehir Belediyesi, Nüfus, http://www.eskisehir.bel.tr/sayfalar.php?sayfalar_ id=16 [odczyt: 22.04 .2016 ].

${ }_{19}$ Do tego należy doliczyć też ponad 2,5 mln studentów studiujących w systemie edukacji zdalnej: Anadolu at a glance, https://www.anadolu.edu.tr/en/about-anadolu/institutional/anadolu-at-a-glance; ESOGU Üniversite Hakkında https://www.ogu.edu.tr/Icerik/Index/ABOUT-About/1/6 [odczyt: 20.04.2016].

${ }^{20}$ H. Babadoğan, dz. cyt., s. 83. 
uczynić z historii, tradycji historycznych i pamięci o przeszłości atut całej prowincji Eskişehiru. Promocyjne teksty, materiały, ulotki przygotowane przez urzędników miejskich przypominają o obecności wielu cywilizacji na tych terenach, m.in. Frygii (z legendarnym królem Midasem), Bizancjum, państwa Seldżuków i Imperium Osmańskiego. Coraz więcej uwagi poświęca się okolicy - obszarom wiejskim, miejscom historycznym, stanowiskom archeologicznym, gdzie dużo więcej jest elementów starożytnego dziedzictwa kulturowego niż na terenie samego miasta. Mała liczba zabytków skłania też lokalnych urzędników do odkrywania lokalnej tradycji i do aktywnego włączania się w trend identyfikowania, chronienia i promowania „niematerialnego dziedzictwa kulturowego".

\section{Wizja miasta europejskiego}

Przemiany w wyglądzie i funkcjonowaniu Eskişehiru z ostatniej dekady zachodzą pod szyldem „europeizacji” miasta. Projekty miejskie często osadzone są w retoryce „standardów europejskich” i odwołują się do europejskich trendów urbanistycznych i pomysłów na rozwiązywanie problemów miejskich. Misja tworzenia z Eskişehiru bardziej „europejskiego” i „nowoczesnego” miasta odróżniającego się swoim charakterem od innych miast tureckich została przyjęta z entuzjazmem przez władze lokalne. Hasło „Eskisehir - Europejskie miasto Turcji” (Türkiye'nin Avrupa Kenti) - widoczne jest na ulotkach, plakatach, reklamach czy przewodnikach. To jednak nie tylko hasło promocyjne, lecz także konkretna wizja modernizacji opartej na standardach i wzorach zaczerpniętych z miast europejskich, dotycząca bardzo wielu obszarów - infrastruktury miejskiej, transportu publicznego, technologii, kwestii społecznych i kultury. Urzędnicy pytani, co znaczy „europejskie miasto” w kontekście Turcji, definiowali je jako „cywilizowane”, „nowoczesne”, przyjazne dla mieszkańców. Niektórzy wspominali też o przeszłości Eskişehiru, który w XIX wieku miał bardziej kosmopolityczny charakter za sprawą różnych mniejszości, które przynosiły z sobą nowości, zainteresowanie wyższą kulturą i przyczyniły się do rozwoju produkcji, przemysłu oraz handlu. Slogan „miasto europejskie” rozumiany jest również jako adaptacja rozwiązań, ale nie tylko z Europy, lecz z różnych części świata. Przedstawiciele gminy brali udział w oficjalnych wyjazdach do różnych miast, m.in. do Strasburga, aby zidentyfikować dobre praktyki, które nadawałyby się do zastosowania w kontekście tureckim. Znana jest też fascynacja burmistrza Wiedniem i jego rozwiązaniami w poszukiwaniu optymalnych kierunków rozwoju. Wizyty te były cenne jako źródło inspiracji ${ }^{21}$.

Po wyborze Büyükerşena na burmistrza metropolii zorganizowane zostały konferencje poświęcone sytuacji miasta, jego potrzebom, problemom i propozycjom rozwiązań. Następnie wybrano projekty do realizacji, wśród których priorytetowe były zwłaszcza: rewitalizacja rzeki Porsuk (il. 2) i rozbudowanie systemu komunikacji

\footnotetext{
${ }^{21}$ H. Babadoğan, dz. cyt.
} 
publicznej, w tym nowoczesnej sieci tramwajowej (EsTram). Realizacja tych i wielu innych projektów okazała się wielkim sukcesem, poprawiając warunki i jakość życia w mieście, szczególnie w jego centralnej części. Znacznie poprawiła wizerunek miasta zarówno wśród jego mieszkańców, studentów, jak i turystów, którzy zaczęli licznie przyjeżdżać do Eskişehiru. Rzeka stała się sercem miasta, symbolem, z którego mieszkańcy są dumni, tym bardziej na ciągnących się wzdłuż niej uliczkach ludzie lubią spędzać wolny czas. Bulwary są miejscem spotkań i rozrywki, a od niedawna pożądanym miejscem do zamieszkania. Odnowiono okolicę, pojawiły się też kolorowe, urokliwe mosty, a wzdłuż rzeki otwarte są kawiarnie i restauracje. Rzeka Porsuk stała się częścią tożsamości lokalnej. W lecie, w sezonie turystycznym, rzeką pływają łodzie i gondole przypominające te z kanałów Amsterdamu czy Wenecji ${ }^{22}$. Wiele inwestycji i projektów nakierowanych było na poprawę estetyki przestrzeni publicznej, zwłaszcza miejsc wcześniej zaniedbanych, opuszczonych czy zniszczonych. Pojawiły się parki miejskie i nowe zagospodarowane tereny zielone. Zbudowano szerokie ulice i ścieżki rowerowe. Tym samym miasto chce się wyróżnić na tle innych ośrodków miejskich Anatolii.

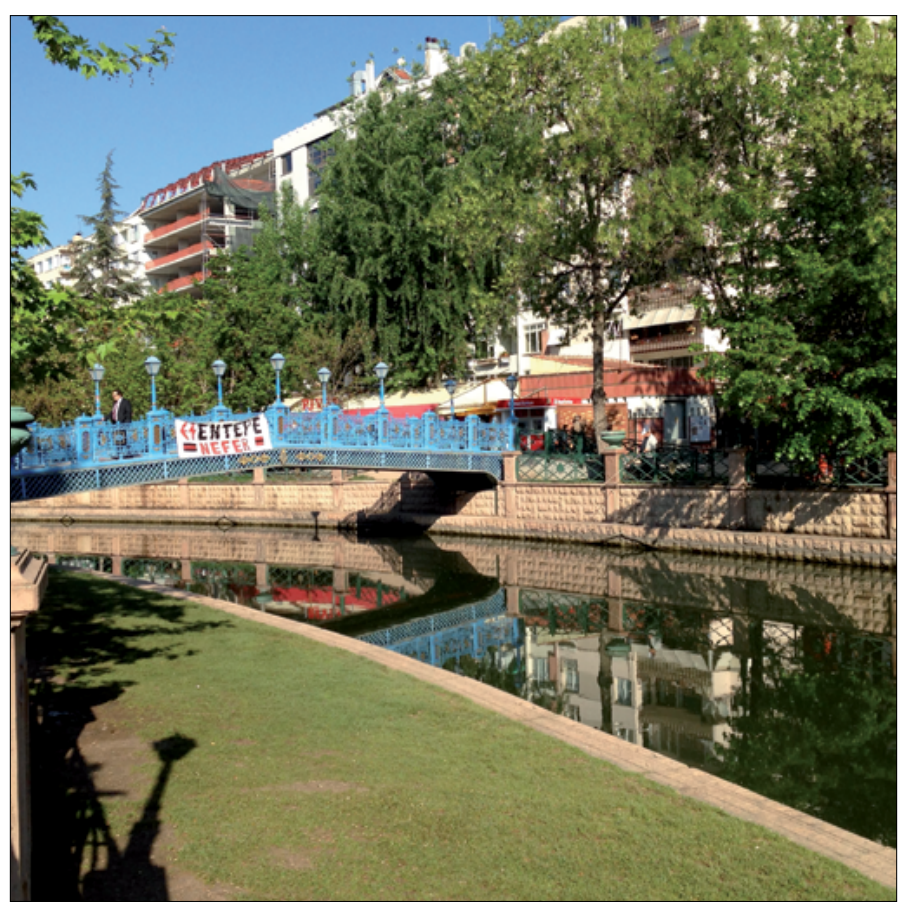

II. 2. Rewitalizacja rzeki Porsuk i okolic

22 Eskişehir Büyükşehir Belediyesi Duyuru Bülteni, Bizim Şehir, nr 19, październik 2008, s. 13, http://www.eskisehir.bel.tr/dosyalar/bizimsehir/19/bizimsehir.pdf [odczyt: 2.06.2016]. 


\section{Miasto sztuki i kultury}

Oprócz działań na rzecz podniesienia poziomu życia w mieście, wyraźne są prace władz lokalnych na rzecz wykorzystania kultury jako narzędzia rozwoju. W obliczu postępującej globalizacji i homogenizacji w sferze kultury w wielu miejscach na świecie poszukuje się sposobów na wyróżnienie danego miejsca, nadanie mu nowej tożsamości. Zyskuje na znaczeniu również trend uczynienia miast bardziej atrakcyjnymi i przyjaznymi dla różnych grup społecznych - mieszkańców, turystów czy mobilnych pracowników szukających inspirującej atmosfery. Cel uczynienia z Eskişehiru miasta sztuki, kultury i nauki wymieniony jest na pierwszym miejscu na liście strategicznych celów miasta. Ambicją władz lokalnych jest utrzymanie pozycji lidera wśród miast tureckich w tych właśnie obszarach. Jednym z planów miasta jest utrzymanie ciągłej działalności teatru miejskiego i orkiestry symfonicznej. Ważne są też muzea, festiwale (tzw. festiwal międzynarodowy, festiwal filmu, teatru, pianki morskiej, sztuki ulicznej i wiele innych), galerie sztuki i wystawy. Duże znaczenie w oficjalnej strategii przypisuje się dziedzictwu historycznemu i kulturowemu - jego rozwijaniu i równoczesnej ochronie. Ostatnim ważnym celem w tej kategorii jest wspieranie edukacji oraz sportu ${ }^{23}$.

Po objęciu urzędu burmistrza przez Büyükerşena, społeczne i kulturowe aspekty rozwoju i planowania stały się jednym z priorytetów, co można wiązać nie tylko $\mathrm{z}$ artystycznymi zainteresowaniami burmistrza, lecz także z jego socjaldemokratycznymi poglądami i wartościami. Regeneracja miasta, inwestycje w obiekty oraz instytucje kultury i sztuki nie są nakierowane przede wszystkim na turystów, ale mają też służyć mieszkańcom. Burmistrz Eskişehiru w promowanej wizji miasta europejskiego podkreśla, że trzeba na nie patrzeć holistycznie i dbać równocześnie o cały wachlarz kwestii miejskich, w tym o kulturę, sztukę i historię ${ }^{24}$.

Miasto postarało się o budowę nowych instytucji kultury, które miały dać impuls dla całego sektora i przybliżyć sztukę mieszkańcom oraz turystom. W ostatnich latach powstały sale koncertowe, zbudowano budynek opery, wsparcie dostały teatr miejski oraz festiwale. Dziś różne wydarzenia kulturalne, teatr, muzyka, pokazy mody, konferencje - wszystko to stanowi ważną część procesu transformacji miasta i jego wizerunku.

Mimo że nazwa miasta - Eskişehir - oznacza dosłownie „stare miasto”, współcześnie ma ono wyjątkowo nowoczesny charakter. Wspomniane wyżej projekty budowy nowych miejsc przeznaczonych na organizowanie wydarzeń kulturalnych dodatkowo podkreślają nastawienie na modernizację miasta. Priorytetem są duże, reprezentacyjne obiekty, które mają być dumą miasta, takie jak np. Park Nauki i Kultury.

W mieście niewiele jest zabytkowych miejsc i budowli, ale te, które są, zyskały nowe życie w ostatnich latach. Władze Eskişehiru przy wielu okazjach podkreślają wielokulturowe historyczne dziedzictwo miasta oraz różnorodność cywilizacji,

${ }^{23}$ Eskişehir Büyükşehir Belediyesi, Kurumsal Vizyonumu ve Misyonumuz, http://www.eskisehir.bel.tr/sayfalar.php?sayfalar_id=7 [odczyt: 2.06.2016].

${ }^{24}$ H. Babadoğan, dz. cyt., s. 131-132. 
które zamieszkiwały tereny centralnej Anatolii od najdawniejszych czasów. Jednocześnie, zwłaszcza w ostatnich latach, wyjątkowo dużo uwagi zwraca się na elementy kultury osmańskiej i tureckiej, zarówno w postaci materialnej, jak i niematerialnej. Ciekawym muzeum - ze względu na zgromadzone eksponaty z regionu od czasów frygijskich (900-550 p.n.e.) oraz formy ich przedstawienia - jest Muzeum Archeologiczne, które przeszło niedawno renowację.

Kluczowym elementem dziedzictwa kulturowego Eskişehiru jest tradycyjna dzielnica z elementami osmańskimi, którą władze lokalne odnowiły i promują jako jedną z głównych atrakcji i dla turystów, i dla mieszkańców. Podobne dzielnice znajdują się w wielu tureckich miastach, jak na przykład w Afyonie lub Kütahyi, ale to dzielnica w Eskişehirze - Odunpazarı zyskała w Turcji na popularności w ostatnich latach i od 2012 roku kandyduje do Listy Światowego Dziedzictwa UNESCO jako „Odunpazarı - historyczny krajobraz miejski”. W dzielnicy tej znajdują się zabytki historyczne, takie jak meczety z epoki seldżuckiej i osmańskiej, m.in. meczet Alaaddin (1271), zespół budowli (külliye) związanych z meczetem Kurşunlu czy tradycyjne drewniane domy (konak), zbudowane przez bogatsze rodziny w późniejszym okresie Imperium Osmańskiego. Zachował się cały układ urbanistyczny, odzwierciedlający sposób budowania i styl życia w tamtej epoce. To najważniejsze zachowane ślady przeszłości w samym mieście. W XX wieku Odunpazarı długo nie było traktowane jako miejsce godne uwagi - w okresie gwałtownej industrializacji nastąpiła zmiana demograficzna i lokalni mieszkańcy wyprowadzali się do nowego centrum miasta i do nowych domów. Mało kto interesował się starymi domami zamieszkanymi w dużej mierze przez przedstawicieli klasy niższej, których nie stać było na remont czy zadbanie o ich wygląd. Wąskie, kręte uliczki dzielnicy nie sprzyjały rozwojowi transportu. Koncepcja konserwacji tych obiektów pojawiła się pod koniec lat siedemdziesiątych, ale dopiero po przyjęciu drugiego planu konserwacyjnego z roku 1997 rozpoczął się proces dynamicznych zmian. Gmina metropolitalna Eskişehir wraz z Gminą Odunpazarı od roku 2000 prowadzą projekty renowacji i rewitalizacji, dzięki którym dzielnica nabrała nowego charakteru - odnowiono fasady budynków i ulice. Wiele domów uzyskało nowe funkcje i są w nich dziś muzea, wystawy, kawiarnie, sklepy z pamiątkami, restauracje, hotele. Niektóre miejsca stają się nowymi centrami debaty publicznej. Odbywają się tam konferencje, wykłady i spotkania ze znanymi ludźmi ${ }^{25}$.

W Odunpazarı (il. 3 i 4) działa również centrum tradycyjnego rzemiosła, w którym jest wskrzeszana prawie od podstaw dawna sztuka, m.in.: kaligrafii, pozłotnictwa, miniatury czy wyrobu tradycyjnych instrumentów muzycznych. Centrum organizuje pokazy dla zwiedzających, a także warsztaty, na których można się kształcić pod okiem nauczyciela-mistrza. W Odunpazarı mieści się też unikatowe w skali światowej Muzeum Pianki Morskiej (Lületaşı Müzesi). Na wystawach prezentowane są wyroby z pianki morskiej, zwłaszcza fajki i figurki, stworzone przez tureckich i zagranicznych artystów, a drobne przedmioty z sepiolitu sprzedawane są turystom,

${ }^{25}$ F. Kolsal, G. Koca, Historical, Physical, and Social Development of Odunpazari, „International Journal of Social Science and Humanity” 2015, 5(6), s. 557-560. 


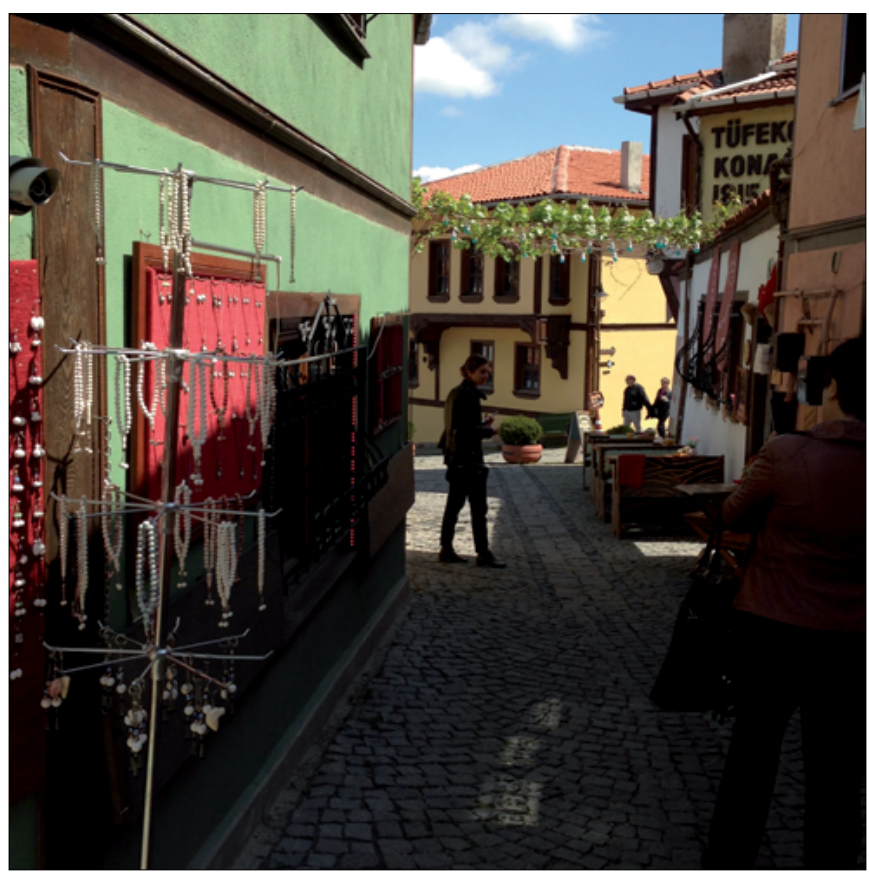

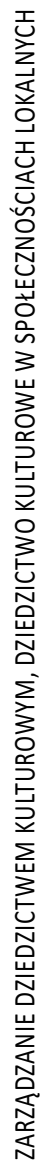

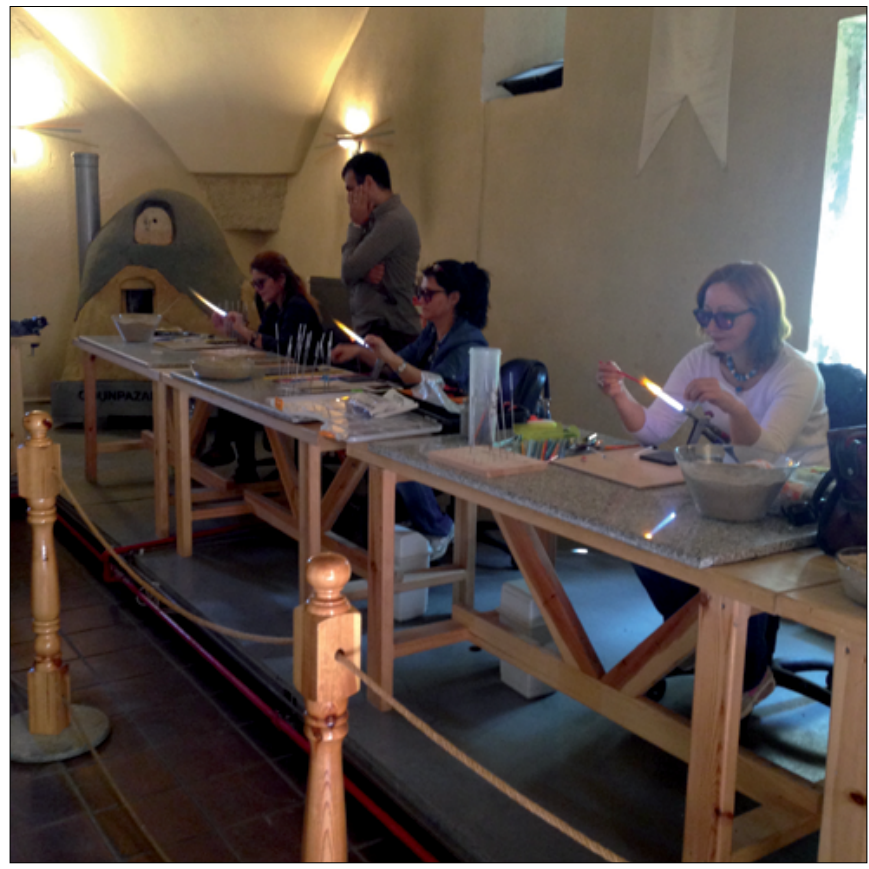

II. 3 i 4. Dzielnica osmańska - Odunpazarı. Rewitalizacja objęła zarówno obiekty materialne, jak i odkrywanie oraz nauczanie lokalnych tradycji (m.in. ceramiki artystycznej) 
dla których ta dzielnica jest najczęściej obowiązkowym punktem programu zwiedzania miasta, zwłaszcza podczas pierwszej wizyty. Popularne jest też muzeum figur woskowych (otwarte w 2013 roku), prezentujące rzeźby znanych postaci tureckich i zagranicznych wykonane przez Büyükerşena i jego pomocników. Za sprawą rewitalizacji Odunpazarı stał się symbolem miasta, znakiem jego historycznych korzeni, przez co budowana jest tożsamość Eskişehiru jako miasta nowoczesnego, ale osadzonego w lokalnej tradycji.

Odnowa starej dzielnicy i prawie zapomnianych tradycji lokalnych wpisuje się w globalny trend nadawania nowych znaczeń i funkcji dziedzictwu kulturowemu, zarówno materialnemu, jak i niematerialnemu. Nie tylko ochrona i utrzymanie status quo się liczy, jak to było dawniej, ale aktywny stosunek do kultury, dający możliwość poszukiwania nowych sposobów na ocalenie części spuścizny.

\section{Odkrywanie „dziedzictwa niematerialnego”}

Mając niewiele materialnego dziedzictwa kulturowego, władze Eskişehiru aktywnie szukają swoich możliwości we współczesnych trendach zainteresowania lokalną spuścizną, tradycjami, sztuką. Dziedzictwo niematerialne staje się w ostatnich latach kolejnym zasobem, które miasto odkrywa i wspiera. Lokalne tradycje, określane coraz częściej „niematerialnym dziedzictwem”, wykorzystywane są w kształtowaniu wizerunku, tworzeniu nowej tożsamości i służą przyciąganiu turystów.

Symbolem międzynarodowego uznania działań miasta w sferze kultury i sztuki było nadanie mu w roku 2013 tytułu „Stolicy Kultury Świata Tureckiego”. Inicjatywa ta, wzorowana na projekcie Unii Europejskiej „Europejskiej Stolicy Kultury”, została zainicjowana w 2010 roku przez Międzynarodową Organizację Kultury Tureckiej (TÜRKSOY). Eskişehir wybrano na stolicę kultury jako drugie miasto w historii tej inicjatywy, po Astanie, której przyznano ten tytuł w roku 2012. W ramach obchodów w Turcji zorganizowano m.in. barwne świętowanie Nowruzu (Nevruz Bayramı), w którym wzięli udział: gubernator prowincji Eskişehir, Kadir Koçdemir, sekretarz generalny TÜRKSOY Dusein Kaseinov, przedstawiciele władz rządowych, a także mieszkańcy miasta. W mowie powitalnej Koçdemir wyraził pragnienie przyciągnięcia ludzi ze świata tureckojęzycznego do Eskişehiru. Międzynarodowe znaczenie tego święta jest tym większe, że w roku 2009 zostało ono dołączone do Listy Reprezentatywnej Niematerialnego Dziedzictwa Kulturowego Ludzkości UNESCO, a rok później Zgromadzenie Ogólne ONZ proklamowało dzień 21 marca „Międzynarodowym Dniem Nowruzu”. Dla Turcji, a zwłaszcza dla Eskişehiru, była to kolejna okazja do promocji swojej kultury i miasta ${ }^{26}$. Rok ten był okazją do organizowania wielu przedsięwzięć i do propagowania koncepcji „dziedzictwa niematerialnego”.

${ }^{26}$ Colourful Nevruz Celebrations in Eskisehir, the Culture Capital of the Turkic World, TÜRKSOY, 8.05.2013, http://www.turksoy.org/en/news/colourful_nevruz_celebrations_in_eskisehir_the culture_capital_of_the_turkic_world-06-07-2013 [odczyt: 5.05.2016]. 
Grupa naukowców oraz studentów z ESOGU zrealizowała projekt badawczy poświęcony identyfikacji lokalnych tradycji regionu, które mogą być uznane za dziedzictwo niematerialne we współczesnym znaczeniu tego słowa ${ }^{27}$.

Również sufizm został zaliczony do „,autoryzowanego" przez UNESCO dziedzictwa niematerialnego. W roku 2005 UNESCO proklamowało Ceremonię Mewlewi Sema - Taniec Derwiszów jednym z „Arcydzieł Ustnego i Niematerialnego Dziedzictwa Ludzkości”, a w roku 2008 wpisało tę suficką tradycję na „Listę reprezentatywną niematerialnego dziedzictwa kulturowego ludzkości”. Narzucona przez Atatürka sekularyzacja osłabiła bractwa sufickie i ich tradycje religijne. Mevlevihane były zamykane, a wykonywanie ceremonii Sema poddano wielu ograniczeniom. Pod koniec XX wieku zapoczątkowany został proces odnowy tych ruchów sufickich w wielu regionach Turcji. W Eskişehir również wzrasta zainteresowanie sufizmem w odniesieniu do lokalnej historii. Ośrodek nauki i praktyki bractwa sufickiego mewlewitów mieści się w historycznej dzielnicy Odunpazarı, gdzie prowadziło ono swoją działalność w latach 1572-1925, będąc wówczas jednym z 12 zborów mewlewickich w Turcji. Obecnie następuje jego rewitalizacja w nowym kontekście i w nowych formach. Opiekę na sufickim dziedzictwem sprawuje Stowarzyszenie Kulturalne Zboru Mewlewickiego (Eskişehir Mevlevihanesi Kültür Derneği), które od 2006 roku działa jako organizacja pozarządowa. Jego celem jest opieka nad tekke, a także promowanie sufizmu i dziedzictwa Rumiego. Wydano książkę o lokalnej historii bractwa, a obecnie regularnie organizowane są koncerty, pokazy tańców derwiszów, tradycyjne spotkania-rozmowy (sohbet) organizuje się różne wydarzenia i wdraża projekty. Można się uczyć gry na tradycyjnych instrumentach sufickich czy wziąć udział w kursach kaligrafii osmańskiej ${ }^{28}$.

\section{Konkurencja między miastami i „efekt Stambułu”}

W ciągu czterech kadencji Büyükerşena jako burmistrza Eskişehiru miasto to przeszło rewolucyjne zmiany $\mathrm{w}$ zakresie urbanistyki, planowania przestrzennego i jakości życia. Projekty inwestycyjne oraz rewitalizacyjne uczyniły z tego średniej wielkości miasta ważny i popularny ośrodek stawiany innym miastom tureckim za wzorcowy model rozwoju. Sondaż przeprowadzony wśród mieszkańców pokazał, że wraz z dążeniem do uczynienia z Eskişehiru miasta kultury i sztuki wzrasta dla nich jego wartość. Bardzo dobrze oceniają oni działania podejmowane przez administrację lokalną na rzecz poprawy życia w mieście ${ }^{29}$.

27 Eskişehir' in Somut Olmayan Kültürel Mirası, A. Koç (red.), Eskişehir Osmangazı Üniversitesi, Eskişehir 2014, http://www.eskisehirkulturelmiras.com/envanter-kitap.php [odczyt: 10.09.2016].

${ }^{28}$ Eskişsehir Mevlevihanesi Kültür Derneği, http://www.eskisehirmevlevihanesi.org [odczyt: 10.09.2016].

${ }^{29} \mathrm{H}$. Samkar, O. Alpu, $M$ regression approach for satisfaction of municipality services: the case of Eskisehir, „Quality \& Quantity” 2013, nr 47(3), s. 1629-1637. 
Wizja miasta europejskiego, w którym kultura, sztuka i dziedzictwo kulturowe mają ważną rolę do odegrania, oraz liczne, ambitne projekty, realizowane przez władze lokalne, uczyniły z Eskişehiru markę, która wpływa pozytywnie na rozwój turystyki. Po roku 2000 liczba turystów systematycznie wzrastała. W 2010 roku do miasta przyjechało 173461 turystów, co było znaczącym wzrostem w porównaniu z 42831 w 2001. To głównie turyści krajowi, a udział gości zagranicznych wynosi zaledwie około $4 \%$ całego ruchu turystycznego ${ }^{30}$. Coraz więcej nadziei i planów wiąże się z rosnącą popularnością turystyki kulturalnej, która przyciąga osoby szukające unikatowych miejsc i doświadczeń. Eskişehir na razie stał się popularnym miejscem odwiedzin dla turystów krajowych, a dużym wyzwaniem i szansą zarazem jest przyciągnięcie turystów zagranicznych. W planach Ministerstwa Kultury i Turystyki Eskişehir jako jedno z 25 miejsc w Turcji został włączony w plany rozwoju turystyki kulturalnej i termalnej. Plan obejmuje Dolinę Frygijską, która nosi ślady starożytnych cywilizacji, zwłaszcza hetyckiej i frygijskiej, a przez swoją historię i dziedzictwo kulturowe ma ogromny niewykorzystany potencjał turystyczny. Afyon, Kutahya, Usak i Eskişehir mają współpracować przy tworzeniu wspólnej strefy rozwoju tych gałęzi turystyki. Turystyka kulturalna ma się rozwijać między innymi ze względu na stanowiska archeologiczne i różne działania na rzecz odnowy historycznych miejsc ${ }^{31}$. Lokalne dziedzictwo kulturowe staje się zasobem do wykorzystania m.in. w celach ściągnięcia turystów i zwiększenia zatrudnienia w branży turystycznej wśród ludności lokalnej.

Według danych Tureckiego Instytutu Statystycznego, w 2013 roku muzea i pozostałości archeologiczne w samym Eskişehirze zwiedziło w sumie 36616 osób. W tym samym roku z 11 publicznych bibliotek skorzystało 301554 chętnych. W 12 teatrach w mieście wystawiono 500 sztuk, w których uczestniczyło 128166 widzów. Administracja prowincji podaje, że w roku 2014 turystów odwiedzających Eskişehir było 500 000, z czego 60000 stanowili goście z zagranicy, którzy przyjechali w celach rekreacyjnych. Najczęściej odwiedzanymi miejscami były: Park Miejski, Park Nauki i Sztuki Sazova, dzielnica Odunpazarı oraz pierwsze w Turcji Muzeum Figur Woskowych $^{32}$.

W niektórych rankingach oceniających jakość życia w miastach Eskişehir znajduje się w czołówce wśród miast tureckich. Na liście najatrakcyjniejszych miejsc do życia w Turcji, przedstawionej przez czasopismo „CNBC-e Business” w 2009 roku, znalazło się ono na drugim miejscu, zaraz po Ankarze i przed Stambułem. Eskişehir dobrze wypadł pod względem wielu wskaźników, a zwłaszcza dużego zainteresowania sztuką wśród mieszkańców. Doceniono też aktywność władz lokalnych w ostatnich latach ${ }^{33}$. Dalsze badania socjologiczne - zarówno badania ilościowe, jak i jakościowe - są potrzebne, aby zobaczyć wpływ zachodzących w mieście zmian, w tym polityk miejskich, na życie mieszkańców. Jakie korzyści widzą oni z uwzględnienia

${ }^{30}$ M. Akoğlan Kozak et al., Eskişehir Turizm Master Planı 2011-2015, Eskişehir: Anadolu Üniversitesi Yayınları 2011.

${ }_{31}$ Ministry of Culture and Tourism of Turkey, Tourism Strategy of Turkey...

${ }^{32}$ M.T. Argan, Eskişehir, Turkey as a crossroads for leisure, travel and entertainment, „Cities" 2016, nr 56, s. 77.

${ }^{33}$ Ankara tops the 'most livable city' list, „Hürriyet Daily News” 2009, nr 9(6). 
kultury w głównych priorytetach miasta? Czy dostrzegają wpływ projektów związanych z kulturą na sferę gospodarczą i społeczną? Czy w ich odczuciu poprawiła się jakość życia w mieście? Jakie skutki przynosi napływ turystów? Te i inne pytania wymagają przeprowadzenia szerszych badań, które pomogłyby dostrzec wpływ transformacji miasta $\mathrm{z}$ różnych perspektyw.

Eskişehir konkuruje z miastami średnimi pod względem liczby ludności. Mimo dużego zaangażowania w uczynienie z kultury i sztuki ważnego czynnika rozwoju miasta, nie jest ono w stanie konkurować ze znanymi na całym świecie metropoliami Turcji. Zjawisko to obrazowo nazywane jest ,efektem Stambułu”. W Regionie Marmaryjskim mieszka ponad 25\% wszystkich mieszkańców Turcji, a w samym Stambule 14,5 miliona (styczeń 2016) i liczba ta stale rośnie ze względu na nieustanną migrację ludności z terenów wiejskich i z mniejszych miejscowości. Podobnie z turystami, których przyciąga status jednej z najważniejszych metropolii świata $\mathrm{z}$ bogatą historią, kulturą, zabytkami i wspaniałą lokalizacją. W roku 2014 miasto to odwiedziło blisko 12 milionów turystów, co stanowiło około $30 \%$ wszystkich wizyt turystycznych do Turcji. Oprócz niepodważalnej pozycji lidera wśród miast tureckich w branży turystycznej, Stambuł jest obecnie głównym ośrodkiem sztuki współczesnej i przemysłów kreatywnych. Przyciąga około 50\% zwiedzających muzea w Turcji, ponad $30 \%$ wszystkich osób w kraju biorących udział w występach i pokazach artystycznych oraz dużo większy procent zainteresowanych sztuką współczesną. Inne miasta, nawet jeśli stawiają na innowacje, inwestują w kulturę i infrastrukturę z nią związaną, nie są w stanie przebić gwiazdy Stambułu. Sytuacja ta dotyka wiele miast, które z kultury i sztuki chcą uczynić narzędzie rozwojowe, m.in. Eskişehiru, Ankary, Izmiru, Diyarbakıru czy Antalyi ${ }^{34}$. Mimo poważnego zaangażowania, które prowadzi do radykalnych transformacji i modernizacji miast, nie są one w stanie dogonić Stambułu pod względem atrakcyjności, liczby zabytków i wizerunku „tureckiej stolicy kultury”. Mogą natomiast, jak to czyni Eskişehir, wykorzystać swoją wyjątkowość i próbować łączyć unowocześnianie miasta z dbaniem o zachowanie przeszłości oraz rozwijaniem sztuki i kultury jako ważnych sfer życia miasta. Taka strategia wpływa pozytywnie na zmianę wizerunku Anatolii, niegdyś traktowanej jako odległy od cywilizacji region, gdzie tylko nieliczni turyści mieli ochotę czy odwagę się zapuścić.

\section{Bibliografia}

Akoğlan Kozak M., Kiliçlar A., Sari Y., Kaşli M., Seçilmiş C., Çiçek D., Zencir E, Eskişehir Turizm Master Planı 2011-2015, Eskişehir 2011.

Aksoy A., A Mindshift [w:] S. Ada, H.A. İnce (red.), Introduction to cultural policy in Turkey, Istanbul 2009.

Anadolu at a glance, https://www.anadolu.edu.tr/en/about-anadolu/institutional/anadolu-at-a-glance [odczyt: 20.04.2016].

${ }^{34}$ Council of Europe, Presentation of the cultural policy..., s. 64, http://www.coe.int/t/dg4/ cultureheritage/culture/Reviews/CDCPP-Bu-2013-2_Turkeyexperts_en.pdf [odczyt: 1.09.2016]. 
Ankara tops the 'most livable city' list, „Hürriyet Daily News” 2009, 9(6).

Argan M.T., Eskişehir, Turkey as a crossroads for leisure, travel and entertainment, „Cities” 2016, nr 56, s. 74-84.

Babadoğan H., Urban project's implementations Towards a European City: A Case Analysis of Eskişehir Greater Municipality, Master Thesis in Urban Policy planning and Local Governments, M.E.T.U, Ankara 2005.

Baraldi B.S., Shoup D., Zan L., Understanding cultural heritage in Turkey: institutional context and organizational issues, „International Journal of Heritage Studies” 2013, nr 19(7), s. $728-748$.

Bazin M., de Tapia S., Turcja. Geografia wschodzacej potęgi, Warszawa 2014.

Colourful Nevruz Celebrations in Eskisehir, the Culture Capital of the Turkic World, TÜRKSOY, 8.05.2013, http://www.turksoy.org/en/news/colourful_nevruz_celebrations_in_eskisehir_the_ culture_capital_of_the_turkic_world-06-07-2013 [odczyt: 5.05.2016].

Council of Europe, Presentation of the cultural policy review of Turkey, Strasbourg 2013, s. 30-32, http://www.coe.int/t/dg4/cultureheritage/culture/Reviews/CDCPP-Bu-2013-2_Turkeyexperts_en.pdf [odczyt: 1.09.2016].

Dönmezer S., An Example of Art-Culture Policy City: Eskişehir, „International Journal of Humanities and Social Science" 2012, nr 2(2), s. 56-62.

Eskişehir Büyükşehir Belediyesi, Başkan Biografi, Prof. Dr. Y1lmaz BÜYÜKERŞEN, http://www. eskisehir.bel.tr/sayfalar.php?sayfalar_id=3 [odczyt: 2.06.2016].

Eskişehir Büyükşehir Belediyesi, Kurumsal Vizyonumu ve Misyonumuz, http://www.eskisehir.bel. tr/sayfalar.php?sayfalar_id=7 [odczyt: 2.06.2016].

Eskişehir Büyükşsehir Belediyesi, Stratejik Plan 2010 (2006-2010), http://www.eskisehir.bel.tr/dosyalar/stratejik_plan/2010.pdf [odczyt: 2.06.2016].

Eskişehir Büyükşehir Belediyesi Duyuru Bülteni, Bizim Şehir, nr 19, październik 2008, http:// www.eskisehir.bel.tr/dosyalar/bizimsehir/19/bizimsehir.pdf [odczyt: 2.06.2016].

Eskişehir Mevlevihanesi Kültür Derneği, http://www.eskisehirmevlevihanesi.org [odczyt: 10.09. 2016].

ESOGU Üniversite Hakkında, https://www.ogu.edu.tr/Icerik/Index/ABOUT-About/1/6 [odczyt: 20.04.2016].

Eskişehir'in Somut Olmayan Kültürel Mirasi, A. Koç (red.), Eskişehir Osmangazi Üniversitesi, Eskişehir 2014, http://www.eskisehirkulturelmiras.com/envanter-kitap.php [odczyt: 10.09 . 2016].

Ince A., Cultural Centers in Istanbul: Changing Cultural Policies in the 2000s [w:] A. Ince (red.), Cultural Policy and Management: Yearbook 2010, Istanbul 2010.

Kolsal F., Koca G., Historical, Physical, and Social Development of Odunpazari, „International Journal of Social Science and Humanity" 2015, nr 5(6), s. 557-560.

Kurpiewska-Korbut R., Dziedzictwo kulturowe jako element promocji międzynarodowej i polityki rozwojowej Turcji, „Zarządzanie w Kulturze” 2012, nr 13, t. 1.

Ministry of Culture and Tourism, Tourism Strategy of Turkey 2013, Ankara 2007, https://www.kultur.gov.tr/Eklenti/43537,turkeytourismstrategy2023pdf.pdf?0\&_tag1=796689BB12A540BE0 672E65E48D10C07D6DAE291 [odczyt: 1.09.2016].

Polo J.-F., Üstel F., Les nouvelles orientations de la politique culturelle turque sous l'AKP, „Pôle Sud-Revue de science politique de l'Europe méridionale" 2014, $\mathrm{nr} 41$.

Samkar H., Alpu O., M regression approach for satisfaction of municipality services: the case of Eskisehir, ,Quality \& Quantity”, nr 47(3), s. 1629-1637.

Wiktor-Mach D., Dziedzictwo kulturowe a rozwój. Dylematy i wyzwania na przykładzie Turcji [w:] K. Jarecka-Stępień, A. Surdej (red.), Tożsamość i efektywność: w poszukiwaniu mechanizmów zrównoważonego rozwoju, Torun 2016. 